\section{ESTUDO DA ASSOCIAÇĀO CLORPROMAZINA + QUETAMINA EM CÃES}

LUCIANO PEREIRA
Médico Veterinário
Hospital Veterinário da Faculdade de Medicina Veterinária e
Zootecnia da USP
JOSÉ LUIZ LAUS
Professor Doutor

Faculdade de Ciências Agrárias e Veterinárias - UNESP

Campus de Jaboticabal

NEWTON NUNES

Professor Assistente

Faculdade de Ciências Agrárias e Veterinárias - UNESP

Campus de Jaboticabal

ANTONIO APARECIDO CAMACHO

Professor Doutor

Faculdade de Ciências Agrárias e Veterinárias - UNESP

Campus de Jaboticabal

PEREIRA, L; LAUS, J.L.; NUNES, N.; CAMACHO, A.A. Estudo da associaçăo clorpromazina + quetamina em cảes. Braz. J. vet Res. anim. Scl., Săo Paulo, v.29, n.2, p.257-65, 1992.

RESUMO: Com o objetivo de avaliar a possibilidade de associaçăo e aplicaçào do cloridrato de quetamina e cloridrato de clorpromazina, por via intramuscular em cảes, foi idealizado o presente experimento. Foram utilizados 10 animais adultos, de ambos os sexos, sem raça definida, $\infty \mathrm{m}$ peso médio de $17 \mathrm{~kg}$. A cada căo toi administrado $1 \mathrm{mg} / \mathrm{kg}$ de peso corporeo de clorpromazina associado, numa mesma seringa, a $15 \mathrm{mg} / \mathrm{kg}$ de quetamina e aplicado por via intramuscular profunda. Foram avaliadas as freqü̈ncias cárdio-respiratórias, temperatura retal, valores/hemogasombtricos, glicemia - traçados eletrocardiográticos, sendo os valores numéricos tratados pelo teste de Tuckey a $5 \%$ de probabilidade. Constatou-se aumento significativo da freqüência cardíaca, alem de constantes supra e infradesnivelamento do segmento ST quando da análise eletrocardiográfica, sendo os demais valores de pouca relevalncia estatistica. Concluiu-se que a associaçăo pode ser empregada em pacientes hígidos, mas pressupdem-se cuidados quando do uso em cães portadores de cardiopatias.
UNITERMOS: Clorpromazina; Quetamina; Arestesia, cảes

\section{INTRODUÇẢO E LITERATURA}

O cloridrato de quetamina, agente anestésico dissociativo derivado das clclohexaminas 21 atua ao nivel central por mecanismos de inibição do sistema corticotalâmico e ativaçāo concomitante do sistema límbico 14,19. Produz anestesia de curta duração 10 caracterizada por perda da consciência, ausência de respostas aos estimulos nociceptivos e manutençāo dos reflexos protetores ${ }^{13}$

Observa-se, ainda, açāo estimulatória sobre receptores alfa adrenérgicos, inibiçăo parassimpática do coraçăo $12,15,19,20,23$ diminuiçăo da resposta pelos barorreceptores e interterencia na captaçăo de norepinetrina pela terminaçăo simpática 2,18 , propriedades sobejamente conhecidas e responsáveis pelo aumento da freqüência e débito cardíaco.

CLARK et al. ${ }^{5}$ (1982) observaram alteraçóes relativas à eletrocardiografia, representadas por depressão do segmento ST e secundárias à hipóxia do miocárdio.

A depressảo respiratória $5,14,17,23, \infty \mathrm{m}$ aumento da capacidade residual e elevaçăo dos niveis de $\mathrm{CO}_{2}$, foi considerada por alguns autores de pouca relevância clínica $^{14}$, mas para outros de grande significado 12,24, fatores estes atribuídos à farmacologia da droga, e fundamentalmente condicionados a pacientes com comprometimento dos mecanismos de homeostasia 5,17

Estudos realizados por NAM 17 (1977) não demonstraram alteraçoes significativas da temperatura corpórea. Observaçỏes análogas nảo se confirmaram nos ensaios de HASKINS ot al. ${ }^{12}$ (1985) os quais notificaram elevaçăo da mesma.

Niveis aumentados de glicose sangüínea foram admitidos por MANZLANO e MANZIANO ${ }^{14}$ (1978) e CLARK ot al. 5 (1982). A coexistência dos efeitos e sous correspondentes estaria relacionada d atividade gliconeogênica da droga ${ }^{13}$ e, nảo menos, à hipoinsulinemia por aumento dos niveis de catecolaminas ${ }^{1}$.

Estudos conduzidos com vistas a determinar os valores reais anestésicos do agente encontraram resultados de importante significado prático. CLARK et al. 5 (1982) e HASKINS et al. ${ }^{12}$ (1985) reportaram relaxamento muscular insuficiente, estado cataleptóide, curto período de anestesia e, em alguns animais, quadros convulsivos foram também lembrados ${ }^{14}$

A somatória dos achados e a adversidade dos efeitos aqui traduzidos limitaram e emprego do fármaco, motivando a busca por alternativas viáveis, práticas e igualmente seguras. Foram propostas associaçōes anestésicas com agentes tranqüilizantes, ansioliticos e miorrelaxantes de ação central. DEPPE et al. ${ }^{7}$ (1982) e FARVER et al. ${ }^{8}$ (1986) 


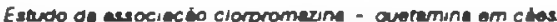

sugeriram empregá-lo em associaçăo com derivados fenotiazinicos, os quaıs sảo sabıdamente potencializadores dos efeitos depressores dos anestésicos gerais 11

Particularmente à clorpromazina, inúmeras foram as citaçóes a respeito de suas propriedades. Constatou-se. entre outras, a capacidade de reduzir o metabolismo basal dimınuir a frequencıa respiratória, exercer ação anti-emética - proporcionar severa hipotensão, resultante dos efeitos sobre vasos periféricos 15 . Incluiram-se entre os efeitos notificados o relaxamento muscular, produto da açăo antidopaminórgica ${ }^{13}$ e quadros de hipotermia oriundos da atividade vasodilatadora periférica e depressora do centro termorregulador 3.9

Relativamente à associaçāo clorpromazina + quetamina, estudos elaborados por DEPPE ot al. 7 (1982) mostraram tratar-se de procedimento anestésico seguro e de grande utilidade prática, sobrepujando, em muito, os efeitos obtidos com a administraçáo isolada do agente dissociativo Reportaram aumento temporal no período de anestesia. relaxamento muscular mais satisfatório e alteraçỏes cádiorespiratorias nảo relevantes. Neste particular, DEPPE et al. 6 (1987) referiram-se a açăo antagónica dos fenotiazinicos frente a quetamina por competiçăo ao nivel dos receptores alfa-adrenérgıcos

Tendo em vista a praticidade $\theta$ as grandes lacunas deixadas nos estudos que procuraram viabilizar a associaçảo dos agentes na prática cotidiana, idealizou-se estudar a combinaçăo das drogas por diluiçào $\theta$ infusăo simultânea em uma mesma seringa

Para a obtençảo de dados conclusivos às proposiçỏes. avaliaram-se os efeitos dos parametros: frequência cardiaca - respiratória. temperatura corpbrea, pH e gases sangüineos (arterial e venoso), eletrocardiografia e glicemia.

\section{MATERLAL E METODO}

Foram utilizados dez căes adultos, sem raça definida, de ambos os sexos, com peso médio de $17 \mathrm{~kg}$. considerados sadios e fornecidos pelo canil do Hospital Veterinário "Governador Laudo Natel", da Faculdade de Ciências Agrárias e Veterinárias - Campus de JaboticabalUNESP, tomando-se o cuidado de se descartarem fêmeas prenhes ou em cio.

Para o estudo dos parámetros de $\mathrm{pH}$, gases sanguineos (arterial e venoso), glicemia, frequência cardiaca - respiratoria, temperatura retal e eletrocardiogratia; os animais selecionados foram, apos protocolados, mantidos por 12 e 24 horas em jejum hidrico $\theta$ alimentar, respectivamente.

Os parâmetros empregados para se estudar os tempos de induçăo e recuperaçăo e o periodo hábil anestésico. consistıram na avaliaçăo da resposta ao estimulo nociceptivo, por pinçamento da membrana interdigital dos membros torácicos e alteraçes comportamentais
A fim de se avaliar a associação clorpromazına + quetamina o sangue arterial foi obtido da artéria temoral esquerda por exposição a canulação cırúrgıca do vaso Os procedimentos compreenderam: tricotomia, antissepsia do campo, infiltraçăo local com $1,5 \mathrm{ml}$ de cloridrato de lidocaina a $2 \%^{\mathrm{a}}$, incisão cutânea, divulsào dos tecıdos subjacentes, individualizaçảo do vaso e cateterismo por meio de dispositivo para infusāo intravenosab, previamente heparinizadoc. A obtençăo do sangue venoso foi conseguida mediante punçăo direta sobre as velas jugular esquerda $\dot{\theta}$ jugular direita. O volume empregado em ambos os procedimentos foi de $; \mathrm{ml}$, colhido anaerobicamente em seringa de vidro heparinizada e levado a análise imediata em aparelho de hemogasometria ${ }^{d}$

Os estudos foram conduzidos em tempos distintos. com inicio momentos antes da aplicação das drogas e a intervalos de $3,10,20,30,40^{\circ}, 50$ e 60 minutos apos as mesmas. As doses correspondentes foram, respectivamente, $1 \mathrm{mg} / \mathrm{kg}$ de cloridrato de clorpromazina ${ }^{\theta}$ e $15 \mathrm{mg} / \mathrm{kg}$ de cloridrato de quetamina', juntos na mesma seringa e aplicados por via intramuscular profunda.

As amostras de sangue destinadas à determinaçáo dos valores glicêmicos foram obtidas por meio de punção direta das veias jugular direita e jugular esquerda, em seringas de vidro previamente heparinızadas $\theta 0$ conteúdo imediatamente conservado em tubo de ensajo contendo fluoreto de sodio. A seguir, o material foi centrifugado para a obtençảo da fraçảo plasmática, sendo submetido à análise pelo método da ortotoluidina 8 . Os tempos destinados ao ensajo compreenderam: avaliaçāo prévia, momentos antes da administraçảo das drogas e aos 10.20.40.60 e 120 minutos que se seguiram. Da mesma forma, as amostras colhidas foram de $1 \mathrm{ml}$.

A determinação dos parametros referentes a temperatura corpórea e frequência cardiaca e respiratória foi obtida por leitura direta em biomonitor ${ }^{h}$. Os períodos proprios de observaço tiveram inicio momentos antes da aplicaçảo dos fármacos e aos 3,10,20,30,40,50 e 60 minutos que se seguiram

Os traçados eletrocardiográficos, destinados à avaliaçåo da freqüência e ritmo, foram monitorizados por derivação precordial $\left(\mathrm{CV}_{6} \mathrm{LL}\right)$ e por derivaçảo de membros (1. II, III, AVR, AVL e AVF em biomonitor' e eletrocardiografo'

\footnotetext{
4 Xylocaina $2 \%$ sem vaso conanctor (Mertol-Lepeit).

9) DIMED (236) CBS-medico cientifica comercio e representaçóes Lua

9 Uquemine - Roche SA

of Coming 165/2 pH/Blood Gas Anayzot

or Ampicetil-Pnodia Farma Lida

7) Kotalar Park Dans Uda

9) Conjunto comercial para determinaça de glicose-Lablera Sistemes Diagnónicos Lide

I7) Bromonitor RFT II-Typ BMT 3221-GDR/W233

i) Biomonnor RFT. Typ ALS-202-GDR

1) Elotrocardiograto RFT. Typ 6 NEK 401 -GDR.
} 
respectivamente. Os tempos convencionados para os traçados foram os mesmos referentes a temperatura corporea e às treqüências cárdio-respiratorias Excepcionalmente, algumas alteraçð̄es, cuja importância sugeriu notificaça, foram transcritas sem que necessariamente estivessem dentro do estabelecido com relaçảo ao tempo inicialmente proposto.

Os dados obtıdos nos estudos temporais de cada parâmetro foram analisados pelo teste de Tuckey a $5 \%$ de probabilidade

\section{RESULTADOS}

O periodo de latência da anestesia foi de $7.6 \pm 1,2$ minutos e o periodo anestésico hábil de $33.7=6.5$ minutos Movimentos voluntários vocalizaçס̄es se manifestaram a partir de $41.3=7.3$ minutos. A capacidade de locomoção com um minimo de ataxia se deu ao redor dos 120 minutos após a administração da associação anestésica. Durante o período de experimentaçăo, os animais permaneceram de olhos abertos e em midriase, com manutençăo dos reflexos palpebral e corneal. O relaxamento muscular foi considerado moderado e nảo se observou emese ou sialorréa. A "lambedura do bigode" foi um fenomeno constante $e_{\text {, }}$ indistintamente, coexistiu nos animais tanto na induçăo como na recuperaçảo. No transcorrer do período anestésico observou-se, entre os animais, relaxamento do esfincter anal em major ou menor intensidade. Casos isolados de nistagmo ocorreram durante a fase indutiva e um único quadro convulsivo foi observado, decorridos 11 minutos após a administraçăo dos fármacos. De maneira geral, a recuperaçăo nảo foi acompanhada por excitaçăo ou delífio.

Os vajores de pH e gasometria do sangue arterial $\bullet$ venoso nảo sofreram variaçỏes estatisticamente significativas entre os períodos de avaliaçăo. Paralelamente, se mantiveram dentro da faixa de normalidade encontrada na espécie 4,16. Estes dados sảo apresentados nas Tab. 1 e 2

Os achados de glicemia, relativamente aos valores basais, mostraram no transcorrer dos periodos de observaçảo. elevaçåo gradativa a partir e no decurso de todas as fases de estudo. Nảo obstante, loram estatisticamente iguais e permaneceram dentro dos limites fisiológicos para a especie, segundo WHITE - LANG 22 (1982) (Tab 3).

Relativamente a atividade cardiaca os valores aumentaram de forma significativa a partir dos 3 minutos e atingiram um máximo aos 10 minutos. No decurso dos tempos que seguiram declinaram gradativamente $\theta$, no tempo de 60 mınutos, năo mais apresentaram diferenças significatıvas, comparativamente ao basai Tab. 4).

Ouanto à temperatura retal, os parâmetros declinaram no decurso dos períodos de avaliaçảo. Nảo obstante. o estudo estatistico revelou ausência de significancia em todas as fases O mesmo pode ser dito em relaçăo à frequência respıratoria (Tab 4).

Os traçados de eletrocardiografia mostraram, em relação à freqüência e ritmo basais, taquicardia sınusal a partir da administraçăo da associaçăo anestésıca Aos 20 minutos e no decurso dos tempos que se seguiram, a frequência cardiaca dimınuiu, tendendo a uma estabilizaçāo em niveis superiores ao basal. Supra $\theta$ intradesnivelamento do segmento ST constituiram fenómenos frequentes, particularmente nas fases de induçăo anestesia (Fig. 1 e 2).

\section{DISCUSSẢO}

A somatbria de anestésicos e procedimentos seguros acrescidos de anestesistas com experiência, dedicaçăo e perseverança, tornam possiveis a realızaçāo de manobras dentro de padrōes técnicos, éticos e, sobreludo. numanitários.

O que se vê hoje 6 , portanto, fruto das incansáveis buscas que de há muito se iniciaram. Nảo terıam outras áreas atingido a modernidade e o tamanho grau de especializaçăo nåo fosse a anestesiologia, cuja importância năo tem precedentes na história da medicina.

Na prática cotidiana năo raro depara-se com situaçōes que pela gravidade obrigam à realizaçāo de procedımentos rápidos. Neste sentido, inúmeros foram os que estabeleceram regras e normas de conduta, dentre as quais se incluem o emprego da analgesia, nas suas mais variadas formas. Tratou-se, neste trabalho, de se investigar a exeqüibilidade da quetamina em associaçăo com a clorpromazina, empregadas simultaneamente em uma mesma seringa. Relativamente à quetamina sảo conhecidos os seus valores, sob determinadas condiçōes. Nảo obstante, discutem-se, ainda, alternativas ou procedimentos adicionaıs voltados a minimizar a colateralidade de eteitos $\theta$ as desvantagens que nảo raro surgem no decurso da anestesia por este fármaco. Incluem-se os trabalhos relacionados ao emprego de derivados fenotiazínicos em associaçăo com a quetamina. DEPPE et al. ${ }^{7}$ (1982) e FARVER et al. ${ }^{8}$ (1986) empregaram-nos na forma de medicação pré-anestésıca. com resultados bastante alentadores.

Estudou-se a associacăo das drogas sob outra forma de aplicaçảo es protocolos experimentais resultaram em dados relevantes. Atteraçóes da hemogasometrı, apesar de nảo significativas, pelos traçados e formas de apresentaçăo permitem admitir tendência à acidose respıratórıa nas tases de induçāo a anestesia. Estes aspectos devem ser considerados, tendo em vista que os pacientes submetidos à experimentaçào mostraram, indistintamente, diminuıçăo do $\mathrm{pH}$ como resultante da bradipneia e aumento do $\mathrm{CO}_{2}$ circulante. Ainda que os fenómenos tenham se manifestado de forma discreta, há que se reforçar que foram constantes A não significancia fruto, talvez, das boas condiçòes 
clínicas dos animais $e$ da efetiva participaçăo dos mecanismos compensatórios 5,17 .

Relativamente à treqüência respiratória, a diminuiçăo de seus valores nas fases de induçăo anestesia, embora năo significativa, merece ser comentada. Acredita-se que os achados desta natureza estariam proximamente correlatos as atividades depressoras dos fenotiazinicos $5,8,12,14,15,17$ A contraposiçăo destes comparativamente aos de DEPPE et al. ${ }^{7}$ (1982) talvez decorra de diferenças na forma protocolar dos ensaios. em que os autores estudaram os eteitos dos fenotiazínicos como pré-medicaçăo à anestesia pela quetamina.

Dimınuição da temperatura retal, gradativa e constante em todas as fases da avaliaçào, poderia ser atribuida à atividade vasodilatadora periférica e depressora do centro termorregulador, proporcionadas pela clorpromazina 3,9

Variaçoses da glicemia foram pouco relevantes. A principio - tendo em vista o jejum prolongado, esta se apresentou baixa, porem, dentro de valores considerados basais 22 . Não obstante, aumentou no decurso dos tempos que se seguiram, sem contudo sobrepujar os limites fisiológicos. Estes achados năo apenas coadunam-se com os de MANZIANO e MANZLANO ${ }^{14}$ (1978) e CLARK et a. 5 (1982), como tamberm com os de JONES et at. ${ }^{13}$ (1987) e AGULAR 1 (1980) sobre a atividade gliconeogenica da quetamina e hipoinsulinemia, por aumento dos níveis de catecolaminas, respectivamente.

O aumento significativo da freqüência cardíaca e do pulso arterial nos períodos de induçào e de anestesia estariam particularmente explicados pela atividade simpatomimetica da quetamina sobre o sistema cardiovascular, aliado ao bloqueio vagal 12,19,20,23. Acredita-se, ainda, que para incriminar a existência de açăo antagónica da clorpromazina, relativamente à quetamina sobre o sistema cardiovascular 6, seriam necessários ensaios adicionais de pressảo arterial, pois os protocolos empregados nảo permitem falar em favor da hipótese.

Ateraçōes como bloqueio atrio-ventricular de $2^{2}$ grau e extra-sistole atrial, constituíram casos isolados e provavelmente "circunstanciais". Em contrapartida, supra e infradesnivelamento do segmento ST foram achados freqüentes. A coexistência de manifestaçăo do tipo em pacientes tratados pela associaçăo, hipoteticamente decorre da hipóxia miocádica por insuficiente preenchimento sangüíneo coronariano 5

\section{CONCLUSOES}

Os resultados obtidos com os protocolos experimentais, permitem admitir:

\footnotetext{
a associação clorpromazina + quetamina pode ser empregada em cảes hígidos:
}

- omprego da associaçào clorpromazina + quetamına pressupóe cuidados em animais cardiopatas e/ou portadores de comprometimento da funçảo respiratória;

- estudos adicionais devem ser induzidos objetivando a exeqüitilidade do procedimento na prática clínicocirúrgica.

\section{AGRADECIMENTOS}

A Fundação de Amparo à Pesquisa do Estado de Sảo Paulo-FAPESP - Proc. 89/3426-8.

PEREIRA, L; LAUS, J.L; NUNES, N.; CAMACHO. A. The etfect of chlorpromazine HCL associated to ketamine HCL in dogs. Braz. J. vet Res. anim. Scl., Săo Paulo, v.29, n.2. p.257-65, 1992.

SUMMARY: The aim of this work was to evaluate the effect of chlorpromazine HCL associated to ketamine HCL on body temperature, heart rate, respiratory frequency, blood gases. glucose levels and eletrocardiography. To ten mongrel dogs, $17 \mathrm{~kg}$ average weight was administered $1 \mathrm{mg} / \mathrm{kg}$. chlorpromazine $\mathrm{HCL}$ and $15 \mathrm{mg} / \mathrm{kg}$ ketamine $\mathrm{HCL}$ mixed in a same syringe and administered into the thigh muscles. The results did not show significant differences among the different parameters but the eletrocardiography did show frequently depression and elevation of the ST segment. Based on behavior and statistical results. the association of both drugs showed to be effective and, therefore, can be used safely in dogs, except those with cardiac diseases.

UNITERMS: Chlorpromazine; Ketamine; Anaesthesia of dogs

\section{REFERENCLAS BIBUOGRÁFICAS}

01-AGULAR, EA.O.G. Funçăo hepática e anestesia. Rev. bras. Anestesiol., v.30. p.67-79, 1980.

02-APPEL, E.; DUDZIAK, R.; PALM, D. Sympathoneuronal and sympathoadrenal activation during Ketamine anesthesia. Europ. J. Clin. Pharmacol. v.16. p.91-5. 1979 apud HASKINS S.C.; FARVER, T.8.; PATZ, J.D. Ketamine in dogs. Amer. J. vet Res., v.46, p.1855-60, 1985.

03-BALDESSARINI. R.J. Medicamentos e o tratamento de doenças psiquiátricas. in: GILMAN. AG.; GOODMAN, 
LS.; GILMAN, A As bases farmacológicas da toraptutica 6.ed. Rio de Janeiro. Guanabara Koogan, 1983. v. 1, p.359.

04-CHEW, J.D.: DI BARTOLA, S.P. Manual of small animal nephrology and urology New York, Churchill Livingstone, 1986.

05-CLARK, DM.: MARTIN, R.A.; SHORT, C.A. Cardiopulmonary responses to Xylazine/Ketamine anesthesia in dog. J. Amer. Anim. Hosp. Ass., v. 18 p.815-21, 1982

06-DEPPE, R.; THIBAULT, J.; GIL. C. Uso de la asociacion Ketamina-Clorpromazina en el perro. Zbl. Vet-Med. A. v.19, p.25-31, 1987 .

07-DEPPE, R.; THIBAULT, J.; MERCADO, P. Uso de la asociacion Ketamina-Clorpromazina en el perro. Z Zl. Vot-Med. A, v.29, p.609-13, 1982.

Q8-FARVER, T.B.; HASKINS, S.C.; PATZ, J.D Cardiopulmonary effects of Acepromazine and of the subsequent administacion of Ketamine in the dog. Amer. J. vet Res., v.47, p.631-5, 1986.

O9GLEED, R.D. Tranquilizers and sedatives. In: SHORT, C.E. Principles \& practice in veterinary anesthesia Baltimore, Willians \& Wilkins. 1987. p.16-23.

10-GLEN, J.B. The use of Ketamine (CL-581) in feline anaesthetic practice. Vot Rec., v.92, p.65-8, 1973.

11-HALL, L.W.: CLARKE, K.W. Anestesia veterinária. 8.ed Sảo Paulo, Manole, 1987, p.55-6.

12-HASKINS, S.C.; FARVER, T.B.; PATZ J.D. Ketamine in dogs. Amer. J. vet Res., v.46, p.1855-60, 1985.

13 JONES, L.M.; BOOTH, N.H.; MC DONALD, LG. Farmacologla e terapeutica em veterintria $4.0 \mathrm{~d}$. Ric de Janeiro, Guanabara, 1987

14-MANZIANO, C.; MANZLANO. J. The combination of Ketamine HCL and Acepromazine maleat as a general anesthetic in dogs. Vet Mod. small Anim. Clln., v.73, p. $727-30,1978$.
15-MASSONE, F. Anestesioiogla veterintirla: farmacologia - técnicas. Rjo de Janeiro. Ed. Guanabara, 1987 p.23,92.

16-MUIR, W.W.; HUBBELL, J.A.E. Mandbook of veterinary anesthesia. St. Louis. The C.V Mosby Company, 1989 .

17-NAM, T.C. Studies on the effect of Ketamine HCL on dogs after bleending. Clinical findings and acid-base balance. Jap. J. vet Sci., v.39, p.273-81, 1977 .

18-NEDERGAARD, O.A. Cocaine-like effect of Ketamine on vascular adrenergic neurones. Eur. J. Pharmacol. v.23, p.153-61, 1973 apud HASKINS, S.C.; FARVER T.B.: PATZ, J.D. Ketamine in dogs. Amer. J. vet Res., v.46, p. 1855-60, 1985.

19-PENDER, J.W. Dissociative anesthesia. J. Amer. Mod. Ase., v.215, p.1126-30, 1971.

20-SHORT, C.E. Principles \& practlce in veterinary anesthesia. Baltimore, Willians \& Wilkins, 1987.

21-WARREN, R.G. Anestesia de animales domesticos. Barcelona, Labor, 1986. p.139,147

22-WHITE, W.J.; LANG, C.M. Clinical laboratory methods in physiologic surgery. In: LANG, C.M. Animal physiologle surgery. 2.ed. Now York. SpringerVerlag, 1982. p.134.

23-WRIGHT, J. Pharmacological effects of Ketamine and its use in veterinary medicine. J. Amer. Vet Med. Ass v.12, p.180-3, 1982.

24DE YOUNG, D.W.; PADLEFORD, R.R.; SHORT, C.E. Dissociative anesthetics in the cat and dog. J. Amer. Vet Mod. Ass., v. 161, p. 1442-5, 1972.

Recebido para publlcaçào em 07/11/91 Aprovado para publicaçào em 19/03/92 
TABELA 1 - Variaçāo dos valores médios do pH e Gases Sangüineos (venoso) em cães submetidos à associaçăo quetamina $(15 \mathrm{mg} / \mathrm{kg})$ + clorpromazina $(1 \mathrm{mg} / \mathrm{kg})$ por via intramuscular profunda $(n=10)$. Jaboticabal, 1990 .

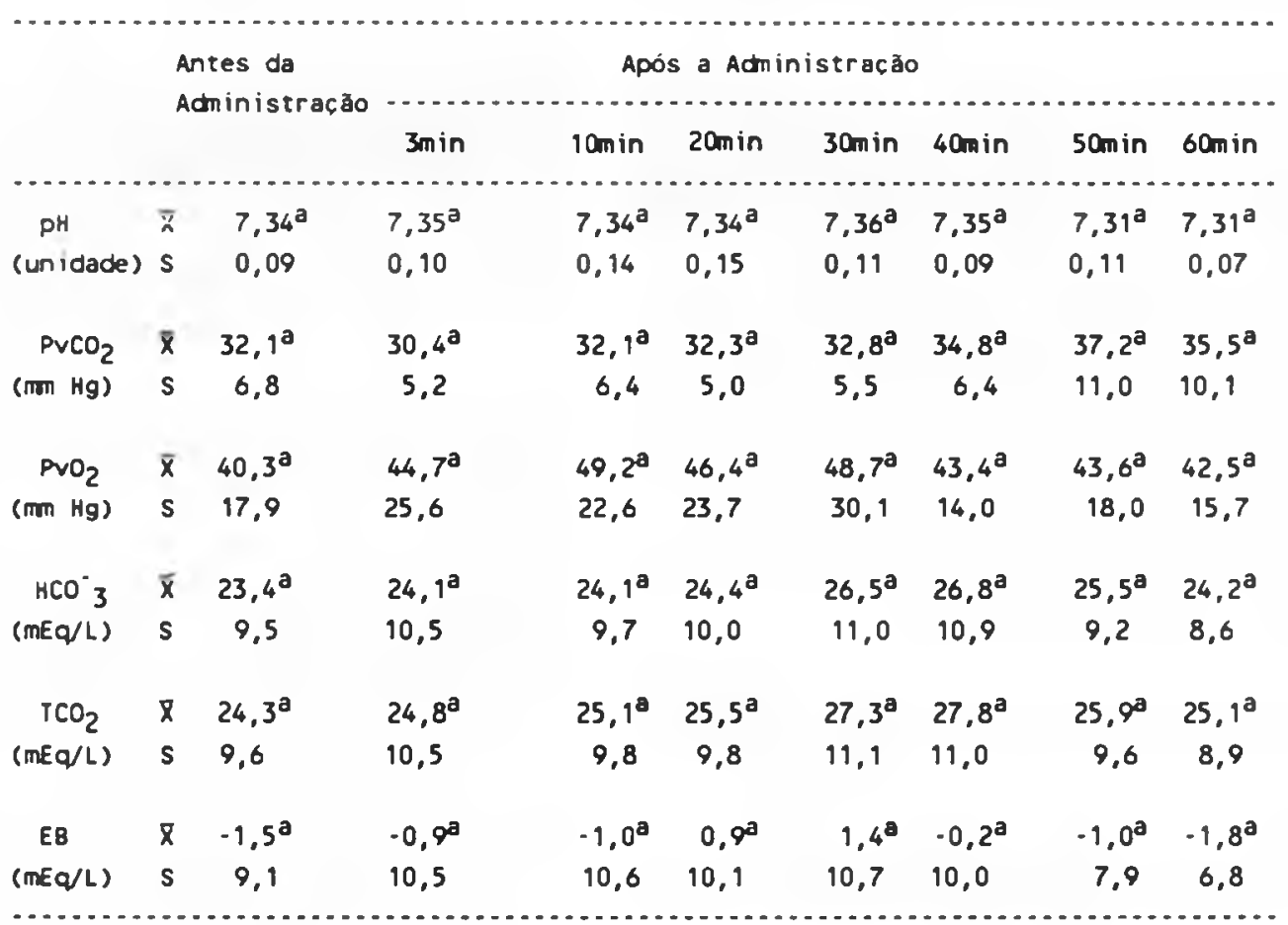

Medias seguidas de mesma letra não diferem entre si pelo teste de Tuckey ao nivel de $5 \%$ de probabilidade. 
TABELA 2 - Variação dos valores médios do pHe Gases Sangüíneos (arterial) em cảes submetidos à associação quetamina (15 mg/kg) + clorpromazina (1 $m g / k g)$ por via intramuscular profunda $(n=10)$. Jaboticabal, 1990

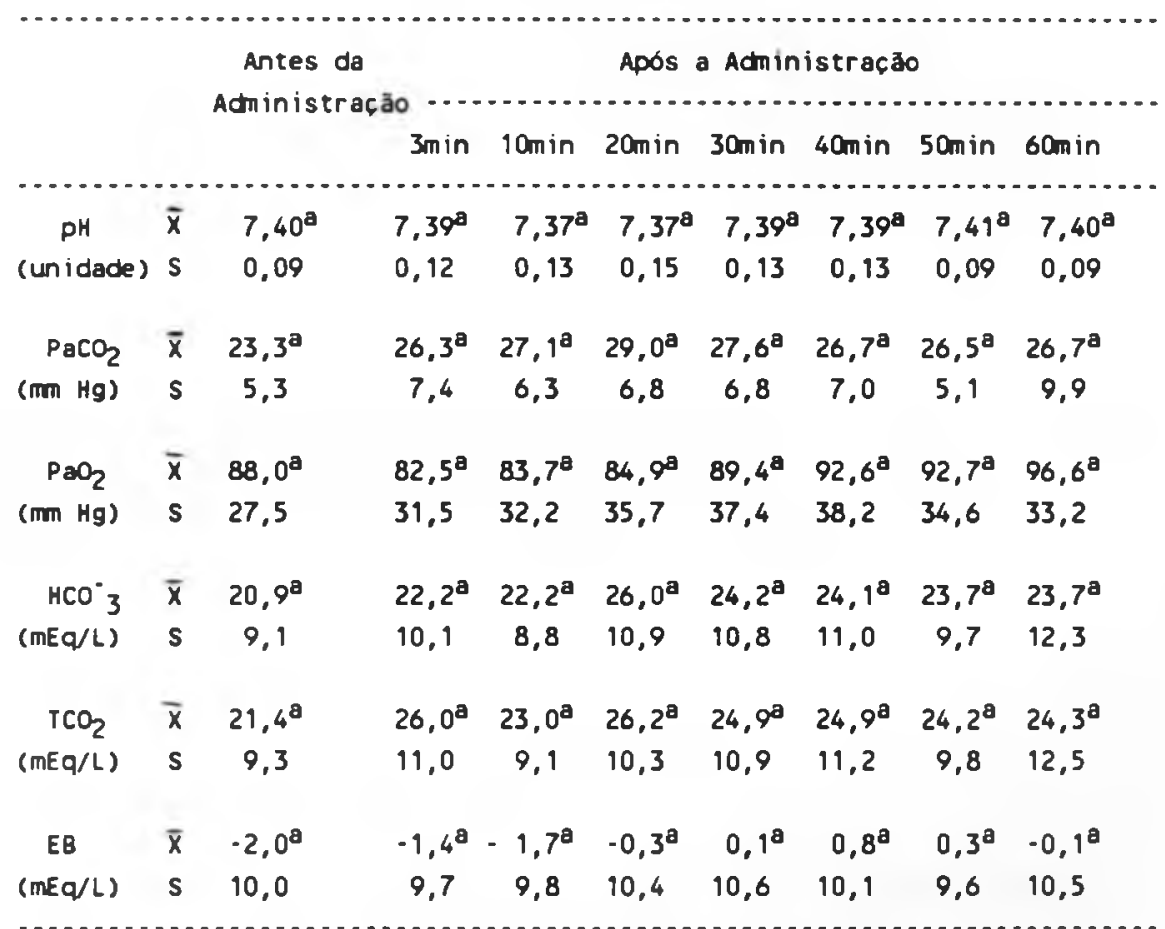

Módias seguidas de mesma letra nåo diferem entre si pelo teste de Tuckey ao nível de $5 \%$ de probabilidade. 
TABELA 3 - Variaçăo dos valores mb́dios da Glicose Sangüinea em cảes submetidos à associaçăo quetamina $(15 \mathrm{mg} / \mathrm{kg})+$ clorpromazina $(1 \mathrm{mg} / \mathrm{kg})$ por via intramuscular profunda $(n=10)$. Jaboticabal, 1990

\begin{tabular}{|c|c|c|c|c|c|c|c|}
\hline \multirow{3}{*}{\multicolumn{3}{|c|}{$\begin{array}{c}\text { Antes da } \\
\text { Adninistraça }\end{array}$}} & \multicolumn{5}{|c|}{ Após a Adninistraçăo } \\
\hline & & & r & $\cdots$ & $\cdots \ldots$ & & 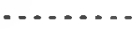 \\
\hline & & & $10 \mathrm{~min}$ & $20 \mathrm{~min}$ & $40 \mathrm{~min}$ & $60 \mathrm{~min}$ & $120 \mathrm{~min}$ \\
\hline se & $\bar{x}$ & $57,50^{\mathrm{a}}$ & $64,26^{a}$ & $63,24^{a}$ & $67.7^{a}$ & $66,24^{\mathrm{a}}$ & $71,35^{a}$ \\
\hline (mg \%) & $\mathbf{s}$ & 9,51 & 10,42 & 11,69 & 14,70 & 15,73 & 15,86 \\
\hline
\end{tabular}

Médias seguidas de mesma letra năo diferem entre si pelo teste de Tuckey ao nivel de $5 \%$ de probabilidade.

TABELA 4 - Variaçōes dos vajores médios da Freqüência Cardiaca (bat./min.). Freqüência Rospiratória (mov./min.) - Temperatura Retal ${ }^{\circ} \mathrm{C}$ ) em cảes submetidos à asscciação quetamina (15 $\mathrm{mg} / \mathrm{kg})+$ clorpromazina $(1 \mathrm{mg} / \mathrm{kg})$ por via intramuscular profunda $(\mathrm{n}=10)$. Jaboticabal, 1990

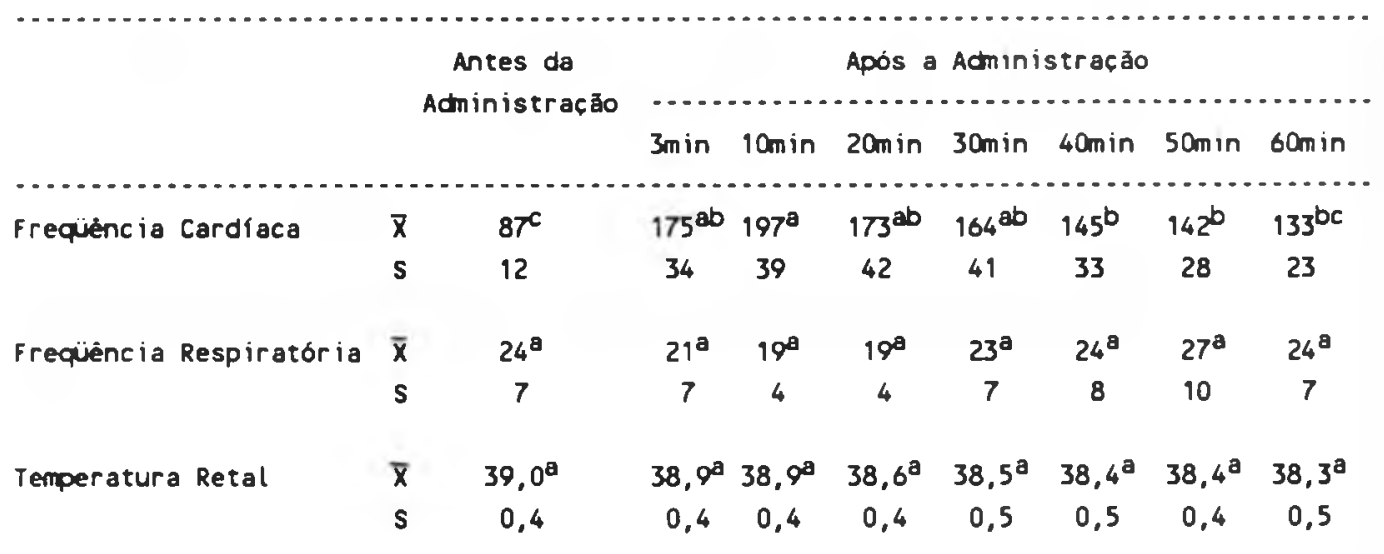

Módias seguidas de mesma letra nảo diferem entre si pelo teste de Tuckey ao nível de $5 \%$ de probabilidade 


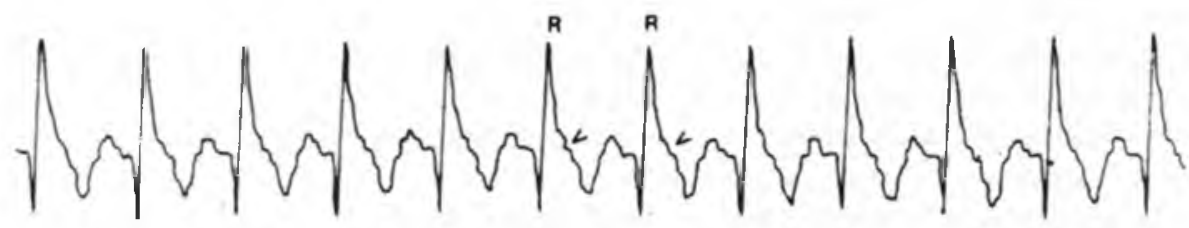

FIGURA 1 - Traçado eletrocardiográfico de um animal, 10 minutos após a aplicaçăo da associaçăo quetamina+clorpromazina. Observar taquicardia sinusal e 0 supradesnivelamento do segmento ST (Derivaçăo $\mathrm{CV}_{6} U$; $V=50 \mathrm{~mm} / \mathrm{s} ; 1 \mathrm{~cm}=1$ $\mathrm{mV}$.

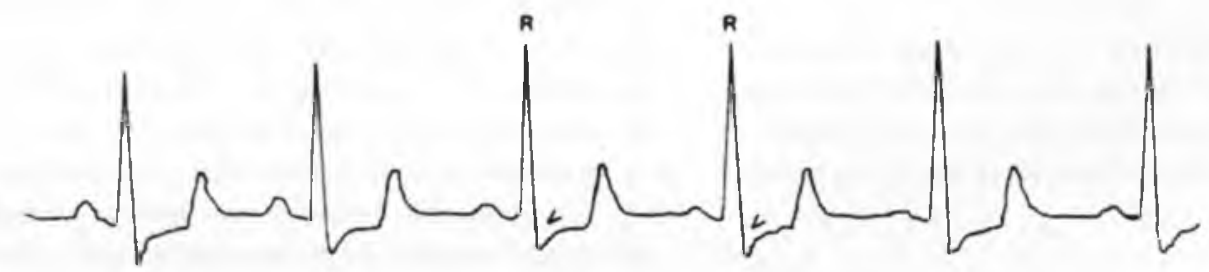

FIGURA 2 - Traçado eletrocardiográfico de um animal, 20 minutos após a aplicaçảo da associação quetamina + clorpromazina. Observar tendência à normalizaçāo da freqǘncia cardíaca e o infra-desnivelamento do segmento ST (Derivaçăo $\mathrm{CV}_{6} \mathrm{Li}_{\text {; }}$ $V=50 \mathrm{~mm} / \mathrm{s} ; 1 \mathrm{~cm}=1 \mathrm{mV}$. 